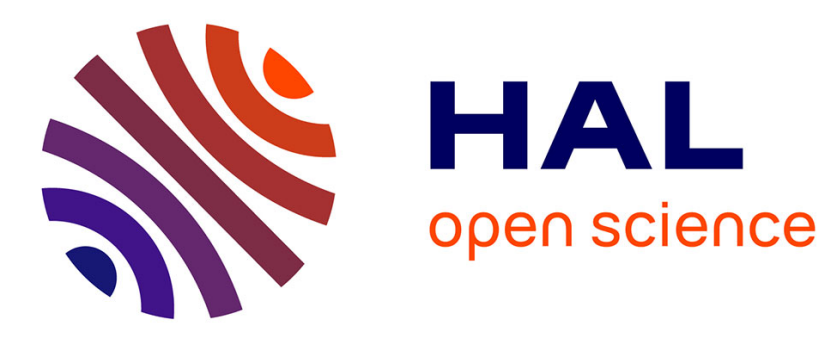

\title{
Innovating pulsed electrophoretic deposition of boehmite nanoparticles dispersed in an aqueous solution, into a model porous anodic film, prepared on aluminium alloy 1050
}

Florent Caubert, Pierre-Louis Taberna, Laurent Arurault

\section{To cite this version:}

Florent Caubert, Pierre-Louis Taberna, Laurent Arurault. Innovating pulsed electrophoretic deposition of boehmite nanoparticles dispersed in an aqueous solution, into a model porous anodic film, prepared on aluminium alloy 1050. Surface and Coatings Technology, 2016, 302, pp.293-301. 10.1016/j.surfcoat.2016.06.009 . hal-01372645

\section{HAL Id: hal-01372645 \\ https://hal.science/hal-01372645}

Submitted on 7 Oct 2016

HAL is a multi-disciplinary open access archive for the deposit and dissemination of scientific research documents, whether they are published or not. The documents may come from teaching and research institutions in France or abroad, or from public or private research centers.
L'archive ouverte pluridisciplinaire HAL, est destinée au dépôt et à la diffusion de documents scientifiques de niveau recherche, publiés ou non, émanant des établissements d'enseignement et de recherche français ou étrangers, des laboratoires publics ou privés. 


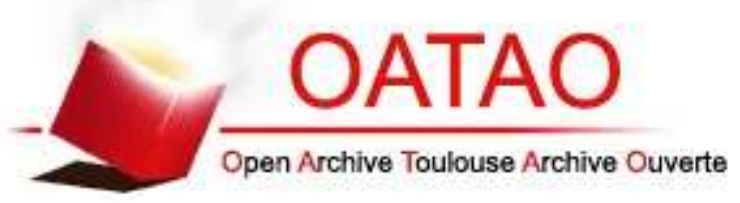

\section{Open Archive TOULOUSE Archive Ouverte (OATAO)}

OATAO is an open access repository that collects the work of Toulouse researchers and makes it freely available over the web where possible.

This is an author-deposited version published in : http://oatao.univ-toulouse.fr/ Eprints ID : 15961

To link to this article : DOI : 10.1016/j.surfcoat.2016.06.009

URL : http://dx.doi.org/10.1016/j.surfcoat.2016.06.009

To cite this version : Caubert, Florent and Taberna, Pierre-Louis and Arurault, Laurent Innovating pulsed electrophoretic deposition of boehmite nanoparticles dispersed in an aqueous solution, into a model porous anodic film, prepared on aluminium alloy 1050. (2016) Surface and Coatings Technology, vol. 302. pp. 293-301. ISSN 0257-8972

Any correspondence concerning this service should be sent to the repository administrator: staff-oatao@ listes-diff.inp-toulouse.fr 


\title{
Innovating pulsed electrophoretic deposition of boehmite nanoparticles dispersed in an aqueous solution, into a model porous anodic film, prepared on aluminium alloy 1050
}

\author{
Florent Caubert, Pierre-Louis Taberna *, Laurent Arurault \\ CIRIMAT, Université de Toulouse, CNRS, INPT, UPS, Université Toulouse 3 Paul Sabatier, Bât, CIRIMAT, 118 route de Narbonne, 31062 Toulouse cedex 9, France
}

Keywords:

Anodic film

Boehmite particles

Electrophoretic deposition

Hydrothermal post-treatment

\begin{abstract}
A B S T R A C T
The present study investigates the pulsed electrophoretic deposition of boehmite particles, previously dispersed in an aqueous solution, into the pores of a model anodic film, prepared using phosphoric acid electrolyte, on an aluminium alloy 1050 (AA1050) substrate. Particles were successfully inserted into the pores, despite some limitations resulting both from the barrier layer, which transpired to be semi-conducting, and from water electrolysis. To address this issue, a pulsed electric field, set to above a threshold value, allowed a current to be sent through the cell, this being accompanied by a reduction of water electrolysis; insertion of particles thus became possible. Scanning Electron Microscope (FEG-SEM) observations, X-Ray Diffraction (XRD) spectroscopy and Electrochemical Impedance Spectroscopy (EIS) studies gave some clues as to the reality of particle impregnation into the pores. Furthermore, an improvement in the porous anodic film filling was achieved using hydrothermal posttreatment.
\end{abstract}

\section{Introduction}

Porous anodic aluminium oxide films have been extensively used as a template for nanorod, nanotube and nanowire growth [1,2]. Overall, growth of these materials is achieved after having filled up the pores with a colloidal dispersion. Pore filling is usually achieved either by dip-coating [3] or electrophoretic deposition (EPD) [1,2,4]. However, as anodic films exhibit a more complicated geometry, the insertion of particles from colloid dispersion without an electric field [5] is more problematic. In such cases, electrophoretic deposition has been reported to be successful for nanoparticle deposition onto non-planar surfaces [6-8].

Usually organic media are used as they provide high ranges of electrode potential [9]. To respond to environmental concerns, an aqueous medium remains a good option. Nevertheless, due to water electrolysis, the cell potential is limited, with the release of hydrogen and oxygen occurring on the electrodes and affecting the quality of the formed deposit $[10,11]$.

To counter this phenomenon, a number of techniques have been studied in the literature. For example, deposition on a palladium substrate is possible in an aqueous medium thanks to the absorption by the palladium of the hydrogen released by electrolysis [12]. Also, Sakurada et al. [13] report that adding hydroquinone into the solution

* Corresponding author.

E-mail address: taberna@chimie.ups-tlse.fr (P.-L. Taberna). increases the deposition weight thanks to its reaction with the $\mathrm{O}_{2}$ gases released. Besra et al. [14,15] can also be cited as having succeeded in reducing bubble formation using a pulsed electric field. So the sol destabilisation due to higher $\mathrm{pH}$ is countered [16].

One key advantage of electrophoretic deposition over other processes such as dip-coating lies in the ability to achieve deposits onto or into substrates characterised by tortuous or complex surfaces. For example, Limmer et al. [1] used an anodic aluminium oxide membrane as a template to ensure nanorod and nanotube growth. Meanwhile, Seo et al. [17] showed how pores could potentially be filled using a dip-coating process, but only a reduced quantity at the bottom of the pores was observed using this method. Kamada et al. [5] studied the insertion of $\mathrm{SiO}_{2}$ particles into anodic films stimulated by an electric field. However, they used an aqueous medium, so due to water splitting, only incomplete filling of the pores was obtained. Fori et al. $[18,19]$ responded to this issue by using an organic based dispersion of $\mathrm{SiO}_{2}$ particles, leading to complete filling of the pores, thus successfully avoiding side reactions such as solvent electrolysis. Despite the difficulties encountered in using an aqueous medium for EDP, Kusdianto et al. [20] reported the potential to fill pores of less than $1 \mu \mathrm{m}$ in length using a pulsed electric field to limit water splitting, while Escobar and al. $[21,22]$ managed to incorporate PTFE particles in $10 \mu \mathrm{m}$ thick anodic film.

It is usually considered that:

- anodic films are made of hydrated alumina $\left(\mathrm{Al}_{2} \mathrm{O}_{3}, \mathrm{xH}_{2} \mathrm{O}\right)$ [23-26]

- the usual hydrothermal sealing (performed just after anodisation in 
hot water at about $98{ }^{\circ} \mathrm{C}$ ) occurs only at the top (i.e. the first 1 or $2 \mu \mathrm{m})$ of the porous anodic films. [27-30]

- the usual hydrothermal sealing of porous anodic films prepared in phosphoric acid based electrolyte is extremely difficult [31], as compared with other types of anodic films.

So there are now two main challenges:

- the first is to insert boehmite (AlOOH) particles all along the pores of the anodic films, in order to promote on the one hand chemical interactions of these particles with the pore walls, and on the other hand complete sealing during final hydrothermal post-treatment.

- the second challenge is to successfully conduct efficient sealing all along the pores of such phosphoric anodic films.

The present work aimed at achieving pulsed electrophoretic deposition of boehmite nanoplatelets dispersed in an aqueous solution into a model porous anodic film prepared by anodisation in a phosphoric acid electrolyte. EPD of the boehmite particles into the anodic film was studied and improved, especially through the investigation of various operational parameters, such as colloidal dispersion conductivity and the type of electric field for electrophoretic deposition. Then, filling of the boehmite particles and sealing of the anodic film were respectively characterised by FEG-SEM observations and XRD analysis, and evaluated by EIS, in relation to its global electrical behaviour.

\section{Experimental methods}

\subsection{Preparation of a model porous anodic film on an AA 1050 substrate}

Aluminium alloy 1050 substrates $(99.5 \% \mathrm{Al},<0.40 \% \mathrm{Fe},<0.25 \% \mathrm{Si}$ and $<0.05 \% \mathrm{Cu}$ ) were treated following a three step procedure (degreasing, etching and acid neutralisation). Firstly, aluminium sheets $(20 \mathrm{~mm} \times 20 \mathrm{~mm} \times 1 \mathrm{~mm})$ were degreased with ethanol. They were then etched by immersion in an $\mathrm{NaOH}$ solution $\left(25 \mathrm{~g} \cdot \mathrm{L}^{-1}\right)$ at $40{ }^{\circ} \mathrm{C}$ for $5 \mathrm{~min}$. and neutralised in an $\mathrm{HNO}_{3}$ solution ( $25 \mathrm{vol} \%$ ) at room temperature for $2 \mathrm{~min}$. After rinsing in deionised water $\left(10^{6} \Omega \cdot \mathrm{cm}\right)$, the aluminium sheets were used as an anode while a lead plate (50 $\mathrm{mm} \times 40 \mathrm{~mm} \times 2 \mathrm{~mm}$ ) provided a cathode. The specimens were galvanostatically anodised in a phosphoric bath $\left(0.4 \mathrm{~mol} \cdot \mathrm{L}^{-1}\right)$ at $25^{\circ} \mathrm{C}$ and at a current density of $1.5 \mathrm{~A} \cdot \mathrm{dm}^{-2}$ for 29 min. Finally, the anodic film obtained was thoroughly rinsed in deionised water. This model porous anodic film, presented in Fig. 1, had a thickness of $9.5 \pm 0.3 \mu \mathrm{m}$ with two layers. The first was made up of linear (and orthogonal to the AA substrate) pores, showing a diameter of $129 \pm 3 \mathrm{~nm}$, while the second was a barrier layer with a thickness of $130 \pm 6 \mathrm{~nm}$.

\subsection{Electrophoretic deposition of boehmite nanoparticles}

A synthesised colloid suspension of boehmite nanoparticles in aqueous media was used. This suspension was prepared by hydrolysis of an aluminium alkoxide, according to the Yoldas process [32]. A supplement of deionised water $\left(\mathrm{H}_{2} \mathrm{O} / \mathrm{Al}=100\right)$ at $85^{\circ} \mathrm{C}$ was quickly added to $25.3 \mathrm{~g}$ of aluminium tri-sec-butoxide $\left(\mathrm{Al}\left(\mathrm{OC}_{4} \mathrm{H}_{9}\right)_{3}\right)$ and stirred for $15 \mathrm{~min}$. The white sol obtained was peptised by adding $0.2 \mathrm{~mol}$ of nitric acid $\left(\mathrm{HNO}_{3}\right)$ per mole of alkoxide in order to control the surface potential on the particles and avoid agglomeration. The mixture was then continuously stirred at $85^{\circ} \mathrm{C}$ for $24 \mathrm{~h}$ using a thermostat system and finally showed a concentration of around $0.5 \mathrm{~mol} \cdot \mathrm{L}^{-1}$. Electrophoretic impregnations of particles into the model anodic film were performed with anodised aluminium as the cathode, while lead foil as the anode was located at about $2.5 \mathrm{~cm}$.

\subsection{Characterisations}

A Transmission Electric Microscope (TEM) was used to measure the particle size and characterise the morphology. The size population was defined by picture analysis using ImageJ software.

Surface and cross-sectional views of the coatings were performed by Field Emission Gun Scanning Electron Microscope (FEG-SEM) in order to prove the possible insertion of particles into the model porous anodic film.

To determine the particle microstructure, the suspension was previously dried in the open air. The xerogel thus obtained was then ground to obtain a powder, which was finally analysed by X-ray diffraction (XRD). XRD analysis was performed with a Brucker AXS D4 ENDEAVOR device using Bragg-Brentano $\theta-2 \theta$ geometry with a copper anticathode $(\mathrm{CuK} \alpha, \lambda=1.541 \AA)$. XRD diagrams were obtained in the $20-100^{\circ}$ (20) range. Peak determination was finally made using the JCPDS card 21-1307, corresponding to an orthorhombic structure boehmite.

The anodic films were characterised by X-ray diffraction at grazing incidence $\left(1^{\circ}\right)$. The measurements were performed in the $20-80^{\circ}$ range using a SIEMENS D5000 device with a copper anticathode $(\mathrm{CuK} \alpha, \lambda=1.541 \AA$ ).

The electric behaviour of the samples was monitored using Electrochemical Impedance Spectroscopy (EIS) during immersion in a neutral solution of $\mathrm{Na}_{2} \mathrm{SO}_{4}\left(0.5 \mathrm{~mol} \cdot \mathrm{L}^{-1}\right)$ at room temperature. A three electrode electrochemical cell was used, with a platinum foil as counterelectrode and a mercury sulphate saturated (saturated calomel) electrode as the reference electrode. The EIS measurements ranged from $10^{5}$ to $5.10^{-2} \mathrm{~Hz}$ and were performed using an SP-150 BioLogic Science Instrument.

Stokes diameters of the nanoparticles were measured by Dynamic Light Scattering using a ZS90 Malvern nanosizer with Zetasizer software.
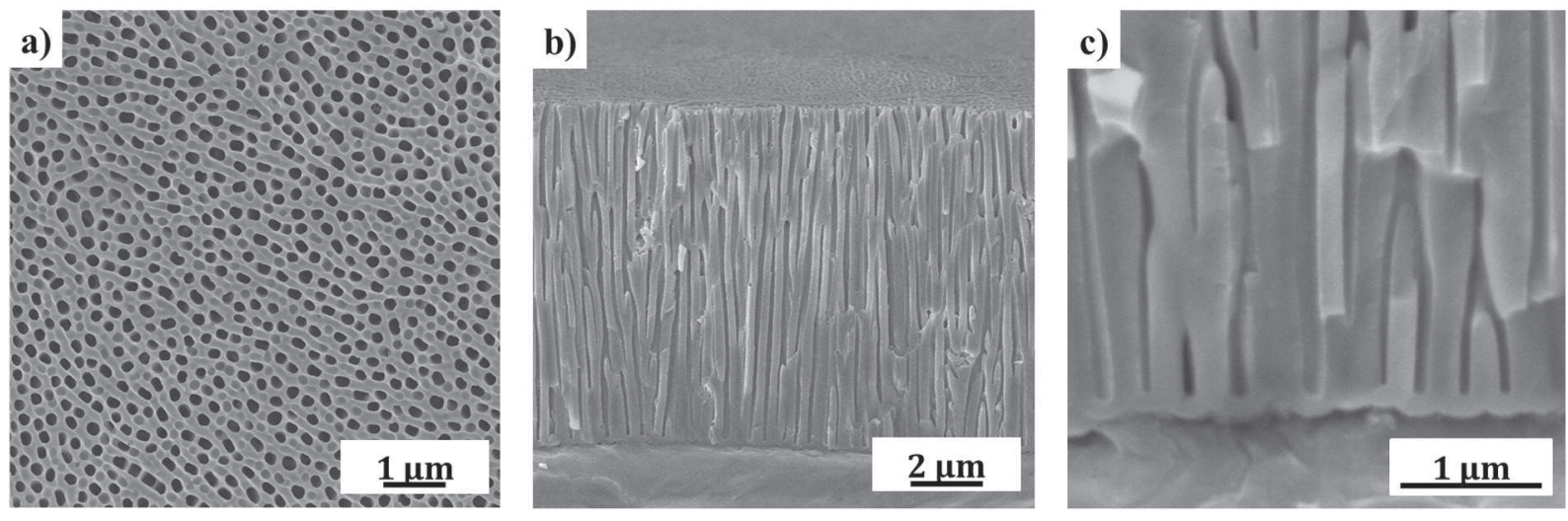

Fig. 1. FEG-SEM a) surface view, b) global cross-sectional view c), bottom cross-sectional view of the model porous anodic film, prepared on AA 1050. 


\section{Results and discussions}

\subsection{Characterisation of boehmite nanoparticles}

Boehmite particles in an aqueous medium were chosen for two reasons. Firstly, as an aqueous based solution it responds to environmental concerns. Secondly, particle chemical composition is very close to the chemical content of the anodic porous film, which may improve chemical affinity. The boehmite particles were synthesised using the Yoldas process and exhibited a needle-like morphology, as previously characterised by Alphonse et al. [33]. An average Stokes diameter for the boehmite particles was about $40 \mathrm{~nm}$ (Fig. 2), which is below the mean pore diameter $(129 \mathrm{~nm})$.

Moreover, as observed in Fig. 3, showing the particles' electrophoretic mobility, a positive value was noted $\left(2.7 \mu \mathrm{m} \mathrm{cm} \cdot \mathrm{V}^{-1} \cdot \mathrm{s}^{-1}\right)$. The latter enables the particles to deposit on the negative electrode (cathode) avoiding any further oxidation of the substrate (i.e. over-oxidation of the anodised aluminium in this case).

Moreover, the XRD pattern (Fig. 4) shows on the one hand that the particles are crystallised, at least partially. On the other hand, Bragg peak indexation is consistent [33] with orthorhombic structure boehmite. In this case, peak (020) is higher than peaks (200) and (002), which difference could be explained by the fact that the distances along the a and $c$ axes are greater than those along $b$, with boehmite having a platelet shape. The crystal structure of boehmite particles could allow their potential identification after impregnation in the anodic film, which is itself amorphous.

\subsection{Particle impregnation into the porous anodic film}

\subsubsection{Impregnation without polarisation}

Impregnation without polarisation is equivalent to dip-coating. The aim is to determine whether the insertion of particles by capillarity into the model porous anodic film is possible spontaneously. To this purpose, dip-coating was performed with a withdrawal rate of $25 \mathrm{~mm} \mathrm{~min}^{-1}$. The FEG-SEM cross-sectional view (Fig. 5a and d) only shows a few particles at the bottom of the pores with none at the top. Additionally, the XRD diffraction patterns obtained, using grazing incidence, respectively for the bare anodic film (Fig 6a) and the impregnated film (Fig. 6b), have very similar shapes. In both cases, there is only one peak (located at about $64^{\circ}$ ), attributed to the underlying aluminium substrate. By contrast, the possible presence of particles within the model anodic film was not demonstrated after dip-coating, despite the crystallised character of the particles in comparison to the amorphous anodic film. In the most optimistic case, the filling rate was so slow

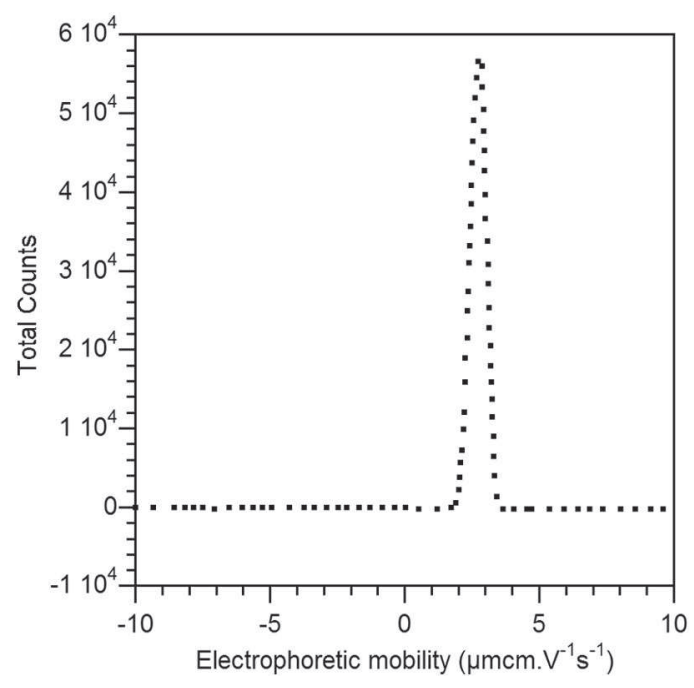

Fig. 3. Electrophoretic mobility of boehmite nanoparticle suspension.

that the particles could not be characterised. Particle impregnation by capillarity does not therefore allow anodic film filling to be obtained.

As shown in Fig. 3 and demonstrated by Diggle et al. [34], as both particles and pore walls are positively charged, particle insertion will be hindered considerably and the pores will therefore only be filled by particle-free solvent. The presence of some particles inside the pores would appear to result from the solvent drying, as already observed by some authors $[35,36]$. This result is consistent with what was reported by Fori et al. [18] and argues in favour of using an electric field to improve the insertion of boehmite nanoparticles into the pores.

\subsubsection{Impregnation by constant and pulsed electric field}

3.2.2.1. Influence of the barrier layer. The challenge here was to determine the appropriate potential range to be applied. On the one hand, too high a potential will lead to gas being released from water electrolysis; on the other hand, anodic films are known to exhibit rather high impedance. As observed in Fig. 7, the current density measured is very low at cell potential lower than $3 \mathrm{~V}$. During the first few seconds of deposition, an exponential decay is observed; this is typically observed behaviour for a capacitive electrochemical interface.

This observation is readily explained by the presence of the barrier layer at the aluminium interface, known to be a dielectric material. In addition, as reported elsewhere [37-39], this layer behaves like an n-

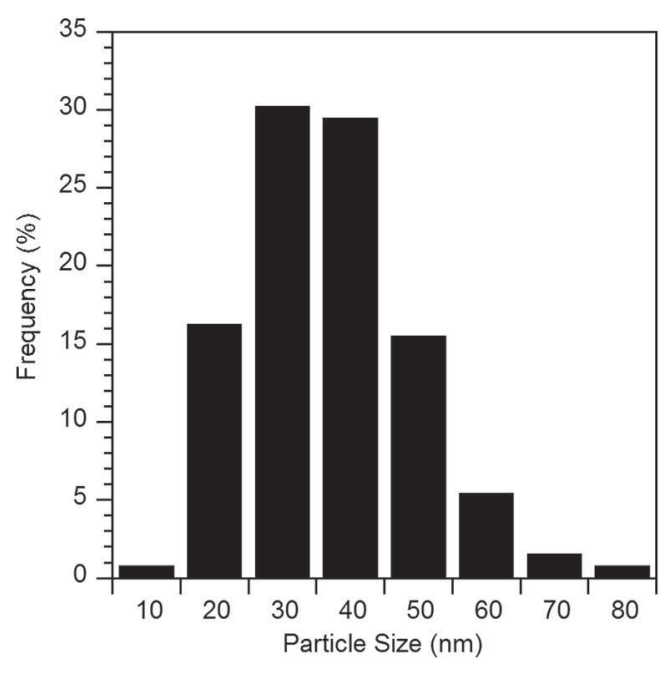

Fig. 2. Particle size distribution.

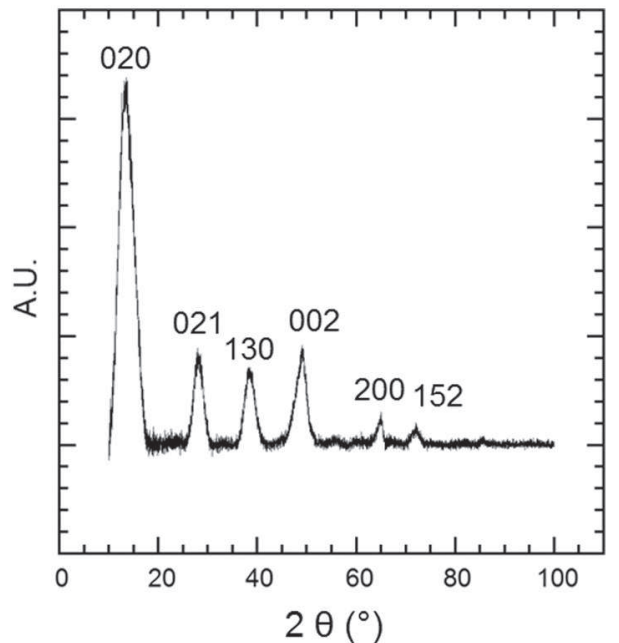

Fig. 4. XRD spectrum of boehmite nanoparticles after drying and grinding. 

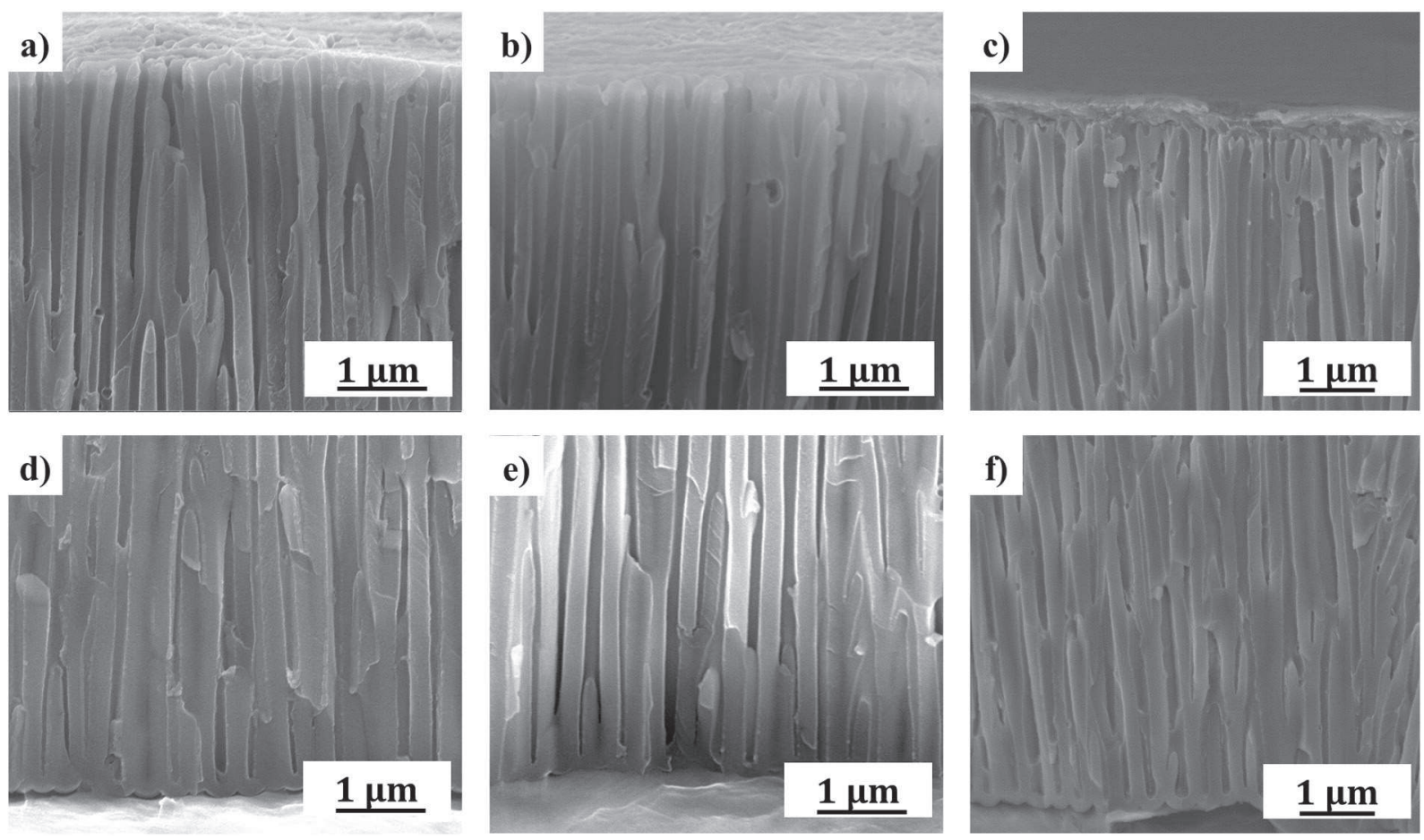

Fig. 5. FEG-SEM cross-sectional views of the model porous anodic film after dip-coating (a) top and d) bottom of the pores), after constant EPD (b) top and e) bottom of the pores) and after pulsed EPD (c) top and f) bottom of the pores).

type semi-conductor with a specific threshold potential depending on the electrolytic medium used during barrier layer formation. Indeed, during the formation of anodic films, anions from the electrolyte (phosphate) and water are incorporated into the barrier layer [23,34] and act as electronic trappers.

To define the threshold potential of the anodic film, an electrochemical impedance spectroscopy study was performed at different potentials in a boehmite dispersion. Firstly, Fig. 8 shows the EIS curves for different applied potentials. As can be seen in the figure, at $\mathrm{f}=10^{5} \mathrm{~Hz}$ and whatever the applied potentials, the value is identical and is known to be the resistance of the electrolyte [40-42]. A dispersion conductivity of $5.35 \mathrm{mS} \cdot \mathrm{cm}^{-1}$ was calculated, while the value measured using a regular conductimeter was $5.11 \mathrm{mS} \cdot \mathrm{cm}^{-1}$.

As reported elsewhere [40-42], the low frequency impedance is driven by the electric behaviour of the barrier layer. This aspect is

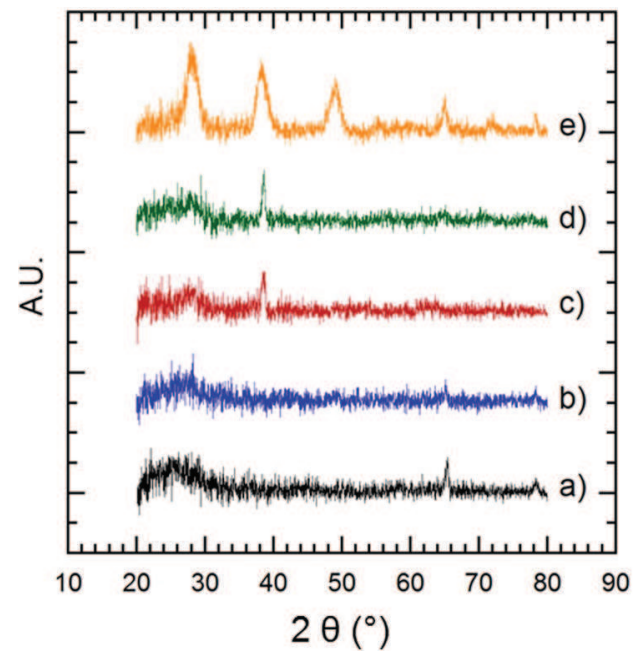

Fig. 6. XRD spectra of a) the bare anodic film, b) after dip-coating, c) after direct EPD, d) after pulsed EDP, e) after pulsed EPD followed by hydrothermal post-treatment. stressed in Fig. 9 where the variation of the low frequency resistance, extracted from the real part of the impedance, is plotted as a function of the applied potential. As expected, the general trend is well described by an exponential decay law $\left(y=2.10^{6} \mathrm{e}^{0.8 \mathrm{x}}, \mathrm{R}^{2}=0.982\right)$, typical for a diode-like behaviour as depicted by other authors [37,38]. These results show that a minimum potential of $-3 \mathrm{~V} / \mathrm{SCE}$ (defined here as the threshold potential) is needed to cause the current to pass through the cell, with the barrier layer becoming conductive. Overall, this kind of behaviour should enable the migration of particles inside the pores.

3.2.2.2. Influence of dispersion conductivity on the threshold potential. Fori et al. [19] have already shown (although in organic media), that to obtain the migration of particles into the pores it was necessary to increase the conductivity of the solution: the interaction between particles and

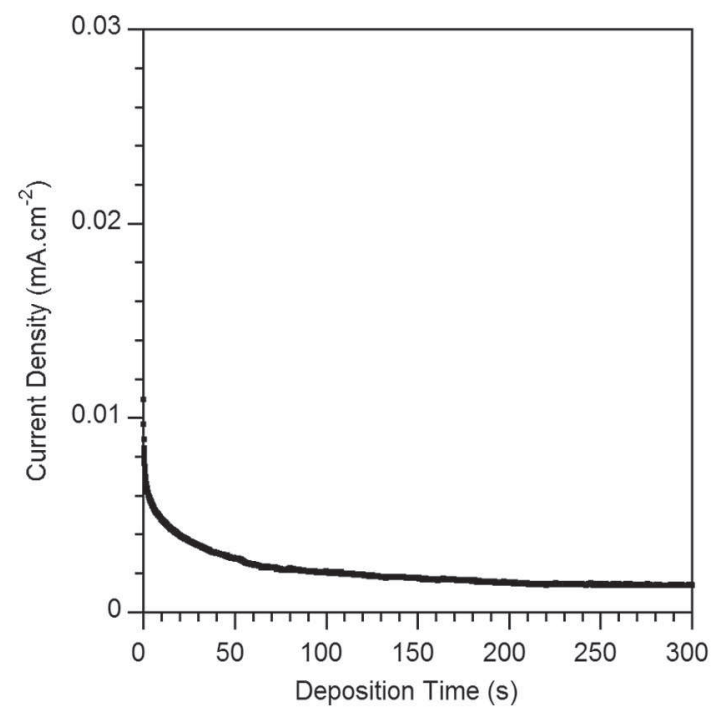

Fig. 7. Current density changes during a constant electrophoretic deposition ( $3 \mathrm{~V}, 5 \mathrm{~min}$ ) of boehmite particles on/in the model anodic porous film. 


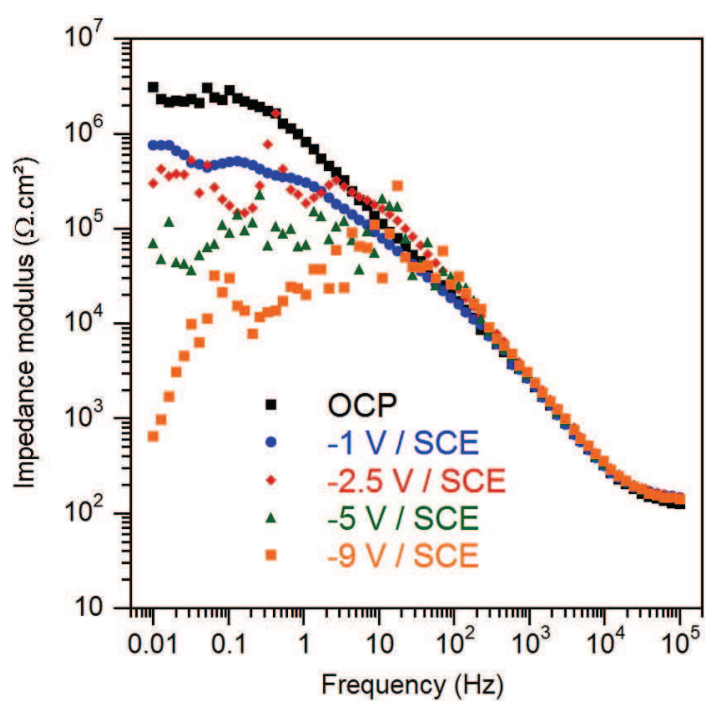

Fig. 8. Variations of impedance modulus (Bode plot) with applied potential, for the bare model porous anodic film immersed in boehmite dispersion.

pore walls is reduced thanks to the electric double-layer compression of both the pore/electrolyte and the particle/electrolyte interfaces. They also demonstrated that increasing conductivity of the dispersion led to focusing the electric field on the anodic film region, improving particle impregnation throughout the anodic film.

Surprisingly, in the case of water-based dispersion, things are rather more complex since the threshold potential appears (Fig. 10) to be related to dispersion conductivity. Somehow, the physico-chemical characteristics of the barrier layer seem to evolve with the dispersion composition. Fig. 10 is obtained by measuring the impedance of an anodic film soaked in dispersions exhibiting different conductivities, achieved by the dilution of a boehmite stock solution with a certain volume of deionised water $\left(10^{6} \Omega \cdot \mathrm{cm}\right)$. As can be seen in Fig. 10, a significant threshold potential variation was observed (ranging from -2 to $-5 \mathrm{~V}$ vs SCE). This is of importance since, when the applied electric field is lower than the threshold potential, deposition into the pores is hindered. Conversely, deposition is possible at lower potential but is accompanied by the reduction of water involving $\mathrm{H}_{2}$ gas release.

On the cathode, a pH increase occurs (the isoelectric point is approximately at $\mathrm{pH} 8[43,44])$ leading to dispersion destabilisation and thus

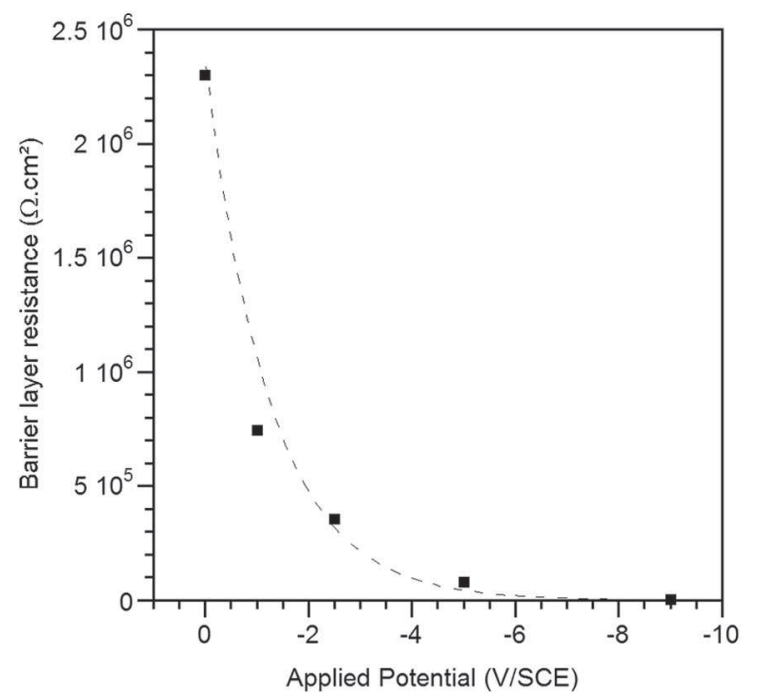

Fig. 9. Barrier layer resistance according to the potential applied during the EIS measurements.

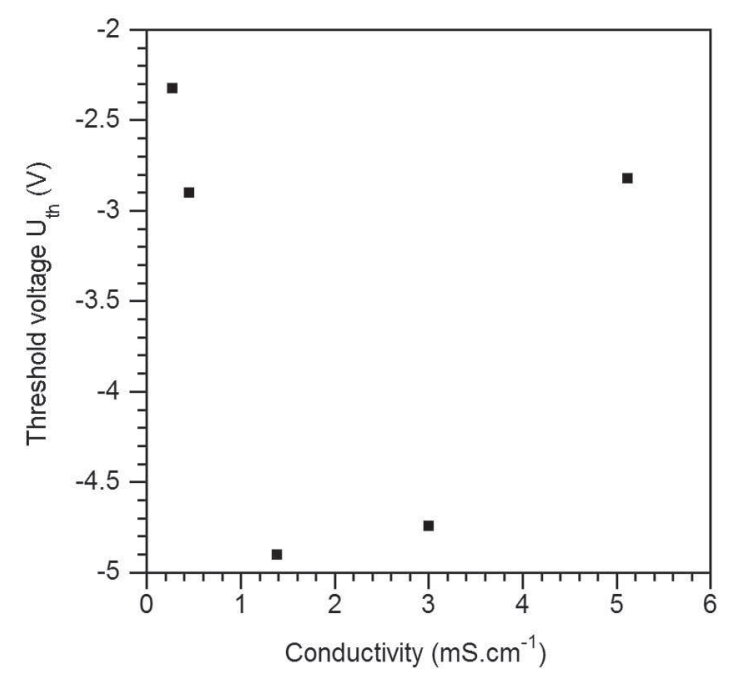

Fig. 10. Threshold potential of barrier layer according to the boehmite suspension conductivity.

aggregation of the particles. Thus, the challenge lies in obtaining sufficient potential to promote particle migration while also hindering bubble formation detrimental to achieving an even deposit, especially with the impregnation of particles into the pores. When conductivity is low, electrolysis is high $\left(\sigma<1.5 \mathrm{mS} \cdot \mathrm{cm}^{-1}\right)$ and most of the deposit is obtained at the surface of the anodic film with this deposit exhibiting poor mechanical stability, whereas dispersion destabilisation is reduced at the interface for high conductivity (lower current). This result suggests that an increase in conductivity limits the influence of water electrolysis on the quality of deposition.

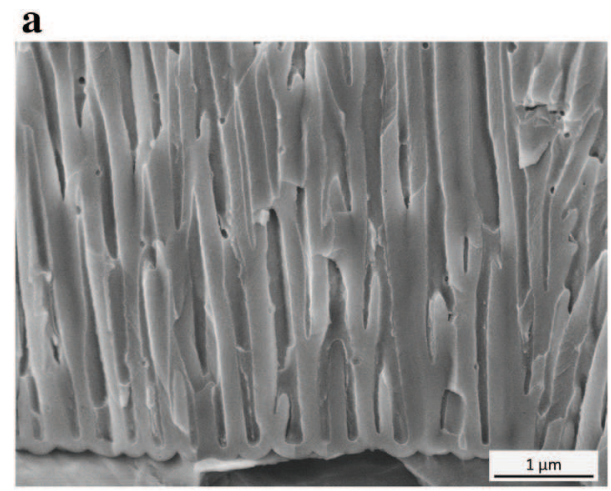

b

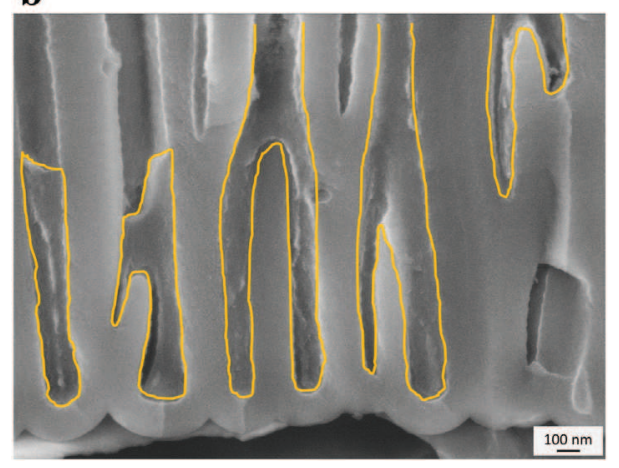

Fig. 11. FEG-SEM cross-sectional (a) global view and (b) bottom view (with the contour of the deposit highlighted in yellow) of the model porous anodic film after pulsed EPD. (For interpretation of the references to colour in this figure legend, the reader is referred to the web version of this article.) 


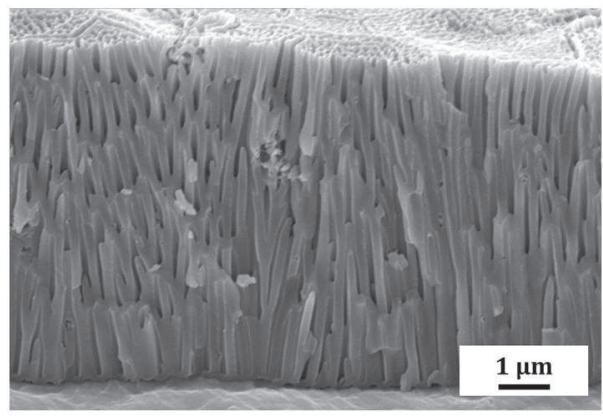

Fig. 12. FEG-SEM cross-sectional view of the model porous anodic film after a hydrothermal post-treatment (deionised water at $98^{\circ} \mathrm{C}, 2 \mathrm{~h}$ ).

When a constant potential close to the threshold potential is applied, hardly any particle insertion is obtained (Fig. $5 \mathrm{~b}$ and e). As observed previously, the presence of particles is difficult to highlight clearly using FEG-SEM observations, and therefore additional XRD analysis was performed (Fig. 6c). The resulting spectrum was compared with that of the bare anodic film and a small peak was observed at an angle of $38^{\circ}$, corresponding to the plane (130) boehmite and suggesting possible insertion of particles within the pores (to be confirmed).

To increase yield, a higher current is required, also meaning a higher potential. However, greater gas release will result, this being detrimental to particle insertion into the pores.

3.2.2.3. Pulsed electrophoresis. To address this issue, Besra et al. [14,15] showed that a pulsed potential leads to a slowdown in gas release while the increase in $\mathrm{pH}$ remained low. They found that a low duty cycle ( $\left.D C=T_{\text {on }} /\left(T_{\text {on }}+T_{\text {off }}\right)\right)$ was preferable to obtain an even deposit. Based on these results, EPD was performed using a DC of $10 \%$, and compared to EPD under constant potential.

In Figs. $5 \mathrm{c}$ and $\mathrm{f}$ and 11, FEG-SEM cross-sectional views of anodic porous film (obtained after a pulsed electrophoretic deposition) show the presence of particles at the bottom of the pores, on the pore walls, along the anodic film and at the top of pores.
The coating was also analysed by X-ray diffraction under grazing incidence (Fig. 6d). The resulting XRD spectrum shows a peak at an angle of $38^{\circ}$, corresponding to the plane (130) boehmite. This result would appear to attest to the possible insertion of particles within the pores of the model anodic film. This peak is also identical (in location and intensity) to that obtained during an electrophoretic impregnation with DC voltage, which raises the question as to the real contribution of a pulsed voltage on the quantity of inserted particles, compared with a DC voltage. However, these characterisations do not allow for a rigorous quantitative analysis of the particles within the pores. Nevertheless, FEG-SEM images (Fig. 11) show that particles are present, and more conclusively so after impregnation under pulsed polarisation.

A mechanism for deposition into pores was proposed by Fukunaka et al. [45] as also by Ponrouch et al. [46]. As application time $T_{\text {on }}$ was limited, only a small amount of hydrogen was produced, preventing any bubbles from coalescing and keeping them small enough to ensure their evacuation during time $\mathrm{T}_{\text {off. }}$. This phenomenon was well described by Ponrouch et al. [46] for cathodic deposition of Ru in anodised aluminium oxide membranes.

The outcome is that using pulsed deposition appears to improve particle incorporation inside the porous anodic film. To take matters further, hydrothermal post-treatment was applied to increase hydration (and so the molar volume) of both the anodic film and the particles and ideally improve pore filling $[29,47]$.

\subsection{Influence of hydrothermal post-treatment}

Chang et al. [48] used hydrothermal synthesis in an autoclave to create aluminium oxy-hydroxide $(\mathrm{AlOOH})$ nanorods and nanotubes in the pores of an anodic film using a phosphoric bath that included aluminium oxalate. The idea was to induce the particles to grow within the pores using hydrothermal post-treatment. The present study pursued this idea by studying the influence of hydrothermal post-treatment (water at $98^{\circ} \mathrm{C}$ for $2 \mathrm{~h}$ ) of the previously prepared samples (i.e. bare anodic film) before and after dip-coating or EPD.

Fig. 12 shows the model anodic film after post-treatment in hot water (i.e. without previous EPD of boehmite particles). No change
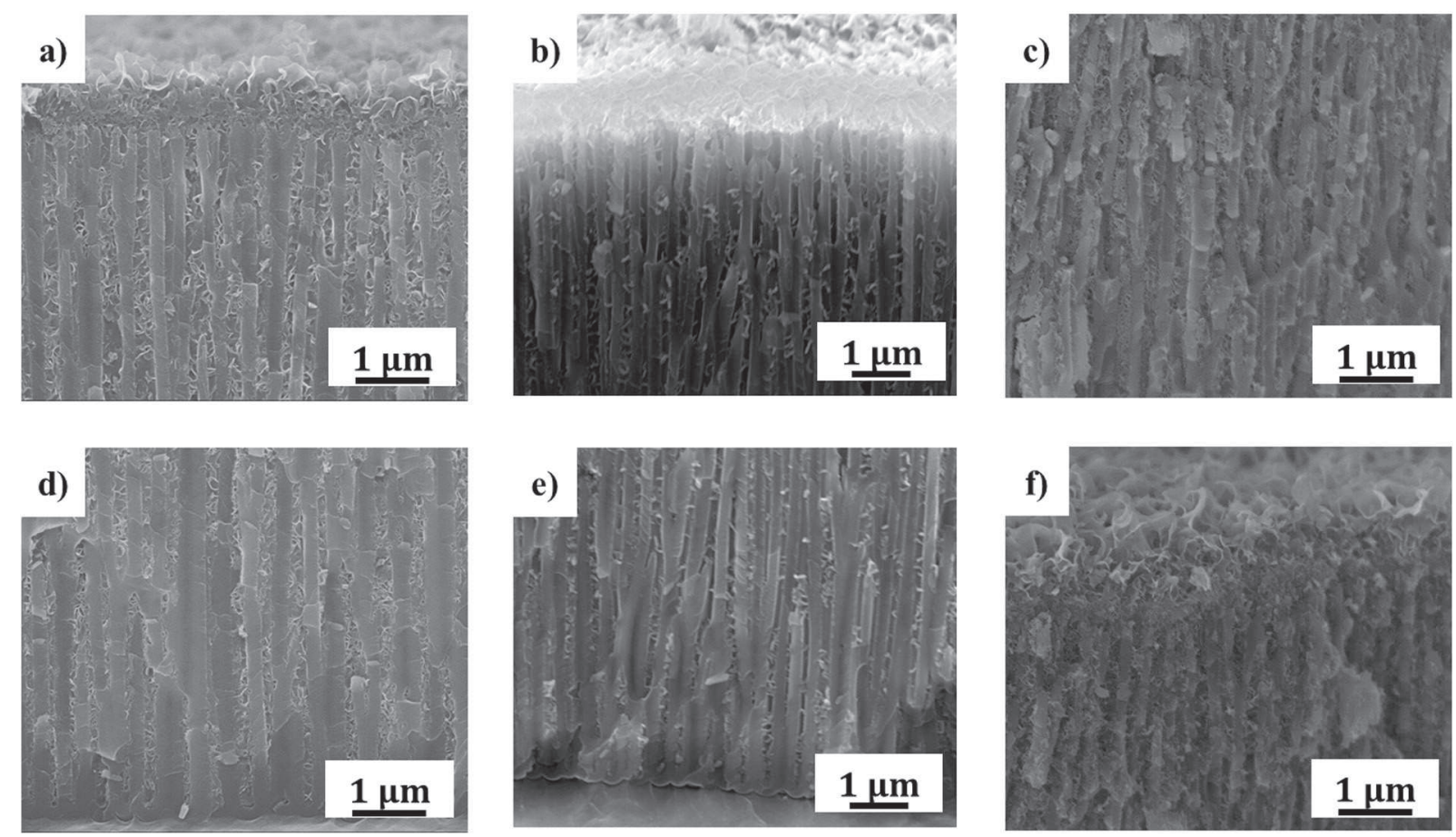

Fig. 13. FEG-SEM cross-sectional views of the model porous anodic film after dip-coating (a) top and d) bottom of the pores), after constant EPD (b) top and e) bottom of the pores) and after pulsed EPD (c) top and f) bottom $\mathrm{f}$ of the pores) and each time with hydrothermal post-treatment (deionised water at $98^{\circ} \mathrm{C}, 2 \mathrm{~h}$ ). 
was observed, showing that the usual hot water sealing is ineffective for this type of anodic film prepared in phosphoric acid electrolyte, as previously claimed [31].

By contrast, for a hydrothermal post-treatment after dip-coating, or continuous or pulsed electrophoretic deposition, filling all along the pores was achieved (Figs. 13 and 14). XRD analysis was also performed to detect the presence of boehmite particles after these various treatments. The XRD spectrum corresponding to the pulsed EPD followed by hydrothermal post-treatment (Fig. 6e) showed several peaks, attributed to those of boehmite. This result suggests that the particles detected after EPD crystallised during hydrothermal post-treatment.

These results seem to confirm either the presence of particles before post-treatment was applied or a deep modification of the anodic film, since it has so far proven practically impossible to clearly observe particles in FEG-SEM observations, whatever the chosen path for insertion, i.e. dip-coating or constant electrophoretic deposition. Possibly, hydrothermal post-treatment acted here as a developer. In all events, it would appear that filling after constant EPD followed by post-treatment was less effective than dip-coating or pulsed EPD. It can be assumed that the larger bubbles formed during the constant potential process may limit particle impregnation. Nevertheless, no clear evidence was obtained regarding the efficiency of pore filling depending on the process. An EIS study was then performed to provide greater insight, since some variations in the impedance are expected with the filling ratio of the pores. Fig. 15 shows the Bode diagrams obtained in $\mathrm{Na}_{2} \mathrm{SO}_{4}$ $\left(0.5 \mathrm{~mol} \cdot \mathrm{L}^{-1}\right)$ for three different modified anodic films: the first by dip-coating and the others by constant or pulsed EPD, all of them being hydrothermally treated in the same conditions.

In Fig. 15, at low frequency $\left(\mathrm{f}<10^{-1} \mathrm{~Hz}\right)$, a decrease in impedance modulus is observed for each process in comparison with the bare anodic film. This value shows a reduction in the barrier layer homogeneity. Electrophoretic and hydrothermal treatments may modify the structure of the barrier layer and, as a result, its electric behaviour [49,50]. Moreover, for non-modified anodic film, as well as modified anodic film by

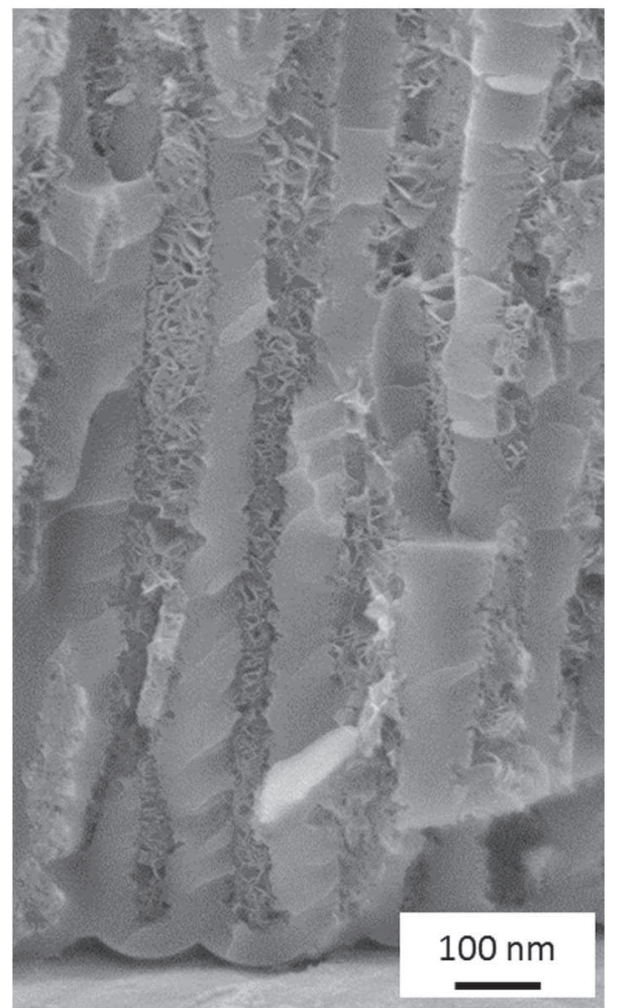

Fig. 14. FEG-SEM cross-sectional view at the bottom of the model porous anodic film after pulsed EPD and hydrothermal post-treatment (deionised water at $98{ }^{\circ} \mathrm{C}, 2 \mathrm{~h}$ ).

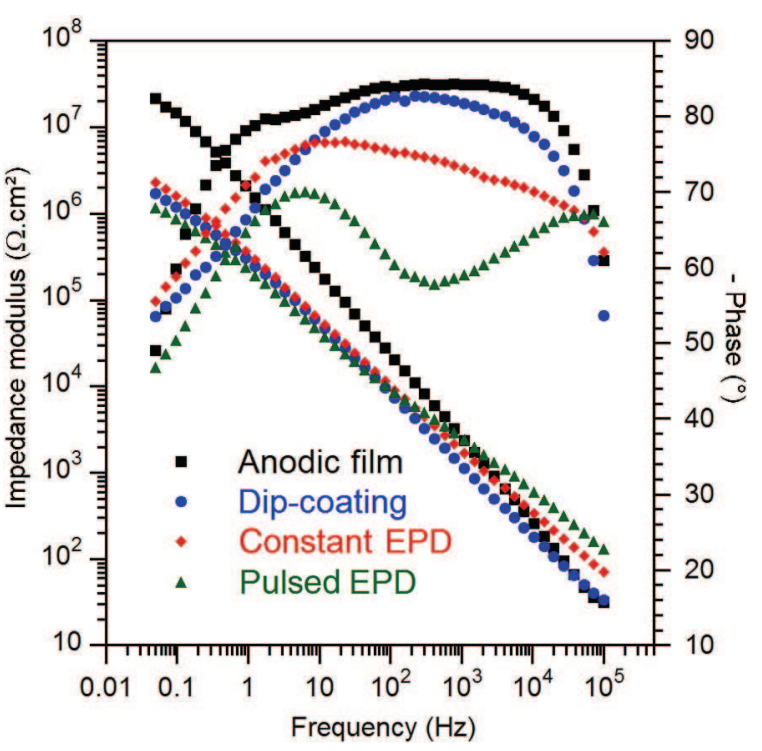

Fig. 15. Variations of impedance modulus (Bode plot) in $\mathrm{Na}_{2} \mathrm{SO}_{4}\left(0.5 \mathrm{~mol} \cdot \mathrm{L}^{-1}\right)$ for the model porous anodic film before and after dip-coating, or constant EPD or pulsed EPD followed each time by a hydrothermal post-treatment (deionised water at $98^{\circ} \mathrm{C}, 2 \mathrm{~h}$ ).

dip-coating and constant EPD, the presence of one time constant only is observed. Mansfeld et al. [51] claimed that when only one time constant is observed, the pores are not completely closed, this being the case for the non-modified porous anodic film. In the case of pulsed EPD, a second time constant is visible in the Bode diagram phase; in the latter case a new time constant clearly emerges for a frequency value close to $5.10^{2} \mathrm{~Hz}$ and gives some clues as to the filling of pores by the growth of particles under hydrothermal treatment.

In previous studies [40-42], the electric behaviour of the anodic film was modelled by an equivalent electric circuit including resistances and capacitances. A classic model is presented in Fig. 16a, where the resistance $R_{\text {elec }}$ denotes the resistance of the electrolyte (bulk and electrolyte entering the pores), $R_{p}$ and $C_{p}$ represent the resistance and capacitance of the porous layer, and $R_{b}$ and $C_{b}$ the resistance and capacitance of the barrier layer. Capacitive behaviour is best simulated by constant phase elements (CPE with a non-perfect capacitance $Q$ and a coefficient $\alpha$ ), while $Q$ is defined by $C=(R \cdot Q)^{1 / \alpha} / R$ where $\alpha$ is the frequency dispersion factor $(0<\alpha<1)$ related to the heterogeneity of layers thanks to the incorporation of alloying elements and penetration of electrolyte during anodisation. When $\alpha=1, \mathrm{Q}$ is a perfect capacitance. In the case of a non-filled porous layer, the equivalent circuit can be simplified as shown in Fig. 16b by the newly introduced resistance $R_{\text {tot }}$, including $R_{\text {elec}}, R_{p}$ and $Q_{p}$ and, as the pores are only filled by electrolyte, $R_{p}$ and $C_{p}$ can be neglected.
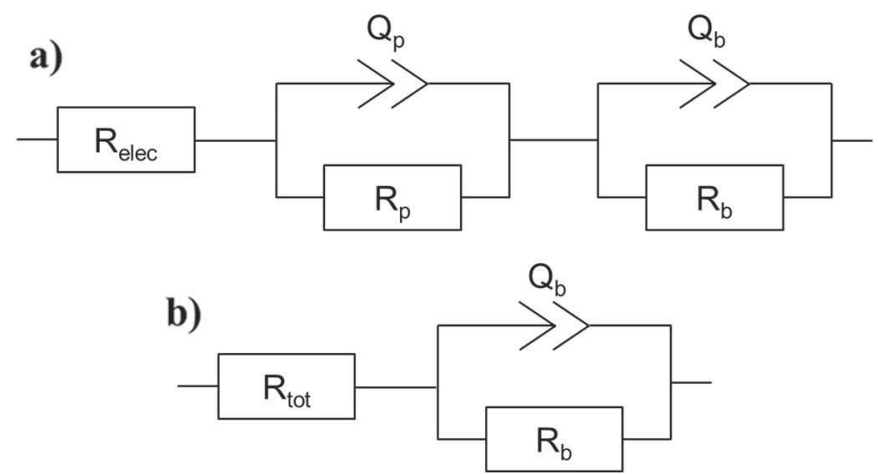

Fig. 16. Equivalent circuits used for modelling the anodic film electric behaviour: a) classic model and $\mathrm{b}$ ) simplified model (for $\alpha=1$ ). 
Table 1

Experimental values of different electric elements of the equivalent electric circuit obtained by fitting of the EIS experimental curves.

\begin{tabular}{lclll}
\hline & $\mathrm{R}_{\text {tot }}\left(\Omega \cdot \mathrm{cm}^{2}\right)$ & $\mathrm{R}_{\mathrm{p}}\left(\Omega \cdot \mathrm{cm}^{2}\right)$ & $\alpha_{\mathrm{p}}$ & $\mathrm{C}_{\mathrm{p}}\left(\mathrm{F} \cdot \mathrm{cm}^{-2}\right)$ \\
\hline Anodic film & 1.77 & $2.98 \cdot 10^{7}$ & 0.96 & $0.92 \cdot 10^{-7}$ \\
Dip-coating + Post-treatment & 14.15 & $1.10 \cdot 10^{17}$ & 0.91 & $1.78 \cdot 10^{-6}$ \\
Constant EPD + Post-treatment & 12.4 & $3.60 \cdot 10^{17}$ & 0.80 & $0.17 \cdot 10^{-3}$ \\
Pulsed EPD + Post-treatment & $1.10^{-11}$ & $2.18 \cdot 10^{4}$ & 0.72 & $0.47 \cdot 10^{-6}$ \\
\hline
\end{tabular}

As explained previously, low frequencies are associated with the barrier layer electric characteristics, whereas the high frequency region concerns the porous layer and electrolyte. To determine the electric behaviour of the porous layer after treatment, impedance curves are fitted into the high frequency field $\left(\mathrm{f}>10^{3} \mathrm{~Hz}\right.$ ). Table 1 summarises the electric element values obtained by fitting using the equivalent electric circuit previously described and observation of the new slope at high frequency $\left(\mathrm{f}=10^{5} \mathrm{~Hz}\right)$ in the case of pulsed EPD. Table 1 highlights a new capacitance $C_{p}$ with a coefficient $\alpha_{p}$. In fact, the value of resistance $R_{p}$ is too high and corroborates the fact that the electric behaviour is always driven by the barrier layer. Sealing, in the case of dip-coating and constant EPD, is not efficient enough (Fig. 15) but the pores are at least partially filled.

EPD allows the resistance of the porous layer to be increased thanks to the growth of particles during post-treatment but proves more efficient when pulsed. These results suggest that there is significant filling of the pores with particles effectively penetrating thanks to pulsed EPD.

\section{Conclusion}

The insertion of boehmite nanoparticles from an aqueous medium into a porous anodic film proved impossible using dip-coating due to electrostatic repulsion between the pore walls and the particles. However, using a combination of electrophoretic deposition and hydrothermal post-treatment, impregnation became possible. This was achieved after assessing the threshold potential of the barrier layer, known to behave like a semi-conductor. This aforementioned threshold potential was found to depend on the conductivity of boehmite dispersion. In an aqueous medium, water electrolysis was seen to be hindered when using pulsed EPD with optimised boehmite dispersion $(\sigma=$ $3 \mathrm{mS} \cdot \mathrm{cm}^{-1}$ ). Hydrothermal post-treatment resulted in complete pore filling, whether dip-coating or electrophoretic deposition was performed, thus revealing the presence of particles within the pores. An additional EIS study confirmed the presence of particles, since a high frequency time constant emerged; the related resistance $R_{p}$ and capacitance $C_{p}$ were linked to porous anodic film filling. This was only observed when a constant or pulsed electrophoretic deposition was applied, proving the need to apply an electric field to assist particle incorporation. In addition, since a higher resistance was measured during the pulsed EPD process, more efficient filling was assumed to be achieved in that case.

\section{Acknowledgements}

The present work was conducted as a part of the ECOREV project. The Regional Councils of Midi-Pyrénées and Mecaprotec Industries are gratefully acknowledged for the financial support $\left(n^{\circ} 11052675\right)$ they provided for this project.

\section{References}

[1] S.J. Limmer, S. Seraji, Y. Wu, T.P. Chou, C. Nguyen, G.Z. Cao, Template-based growth of various oxide nanorods by sol-gel electrophoresis, Adv. Funct. Mater. 12 (2002) 59-64.

[2] G. Cao, Growth of oxide nanorod arrays through sol electrophoretic deposition, J. Phys. Chem. B 108 (2004) 19921-19931.
[3] S. Hirai, K. Shimakage, M. Sekiguchi, K. Wada, A. Nukui, Zirconium oxide coating on anodized aluminum by the sol-gel process combined with ultraviolet irradiation at ambient temperature, J. Am. Ceram. Soc. 82 (1999) 2011-2015.

[4] B.B. Lakshmi, C.J. Patrissi, C.R. Martin, Sol-gel template synthesis of semiconductor oxide micro-and nanostructures, Chem. Mater. 9 (1997) 2544-2550.

[5] K. Kamada, H. Fukuda, K. Maehara, Y. Yoshida, M. Nakai, S. Hasuo, et al., Insertion of $\mathrm{SiO}_{2}$ nanoparticles into pores of anodized aluminum by electrophoretic deposition in aqueous system, Electrochem. Solid-State Lett. 7 (2004) B25-B28.

[6] O.O. Van der Biest, L.J. Vandeperre, Electrophoretic deposition of materials, Annu. Rev. Mater. Sci. 29 (1999) 327-352.

[7] A.R. Boccaccini, O. van der Biest, J.B. Talbot, "Electrophoretic Deposition, Fundamentals and Applications", The Electrochemical Society, Pennington, US, 2002.

[8] L. Besra, M. Liu, A review on fundamentals and applications of electrophoretic deposition (EPD), Prog. Mater. Sci. 52 (2007) 1-61.

[9] L. Stappers, L. Zhang, O. Van der Biest, J. Fransaer, The effect of electrolyte conductivity on electrophoretic deposition, J. Colloid Interface Sci. 328 (2008) 436-446.

[10] M.S. Djošić, V.B. Mišković-Stanković, D.T. Janaćković, Z.M. Kačarević-Popović, R.D. Petrović, Electrophoretic deposition and characterization of boehmite coatings on titanium substrate, Colloids Surf. Physicochem. Eng. Asp. 274 (2006) 185-191.

[11] B. Neirinck, J. Fransaer, O.V. der Biest, J. Vleugels, Aqueous electrophoretic deposition in asymmetric AC electric fields (AC-EPD), Electrochem. Commun. 11 (2009) 57-60.

[12] F. Tang, T. Uchikoshi, K. Ozawa, Y. Sakka, Electrophoretic deposition of aqueous nano- $\gamma-\mathrm{Al}_{2} \mathrm{O}_{3}$ suspensions, Mater. Res. Bull. 37 (2002) 653-660.

[13] O. Sakurada, K. Suzuki, T. Miura, M. Hashiba, Bubble-free electrophoretic deposition of aqueous zirconia suspensions with hydroquinone, J. Mater. Sci. 39 (2004) 1845-1847.

[14] L. Besra, T. Uchikoshi, T.S. Suzuki, Y. Sakka, Bubble-free aqueous electrophoretic deposition (EPD) by pulse-potential application, J. Am. Ceram. Soc. 91 (2008) 3154-3159.

[15] L. Besra, T. Uchikoshi, T.S. Suzuki, Y. Sakka, Pulsed-DC electrophoretic deposition (EPD) of aqueous alumina suspension for controlling bubble incorporation and deposit microstructure, Key Eng. Mater. 412 (2009) 39-44.

[16] L. Besra, T. Uchikoshi, T.S. Suzuki, Y. Sakka, Experimental verification of pH localization mechanism of particle consolidation at the electrode/solution interface and its application to pulsed DC electrophoretic deposition (EPD), J. Eur. Ceram. Soc. 30 (2010) 1187-1193.

[17] I. Seo, C.-W. Kwon, H.H. Lee, Y.-S. Kim, K.-B. Kim, T.-S. Yoon, Completely filling anodic aluminum oxide with maghemite nanoparticles by dip coating and their magnetic properties, Electrochem. Solid-State Lett. 12 (2009) K59-K62

[18] B. Fori, P.-L. Taberna, L. Arurault, J.-P. Bonino, C. Gazeau, P. Bares, Electrophoretic impregnation of porous anodic aluminum oxide film by silica nanoparticles, Colloids Surf. Physicochem. Eng. Asp. 415 (2012) 187-194.

[19] B. Fori, P.L. Taberna, L. Arurault, J.P. Bonino, Decisive influence of colloidal suspension conductivity during electrophoretic impregnation of porous anodic film supported on 1050 aluminium substrate, J. Colloid Interface Sci. 413 (2014) 31-36.

[20] K. Kusdianto, M.N. Naim, K. Sasaki, I.W. Lenggoro, Immobilization of colloidal particles into sub-100 nm porous structures by electrophoretic methods in aqueous media, Colloids Surf. Physicochem. Eng. Asp. 459 (2014) 142-150.

[21] J. Escobar, L. Arurault, V. Turq, Improvement of the tribological behavior of PTFE-anodic film composites prepared on 1050 aluminum substrate, Appl. Surf. Sci. 258 (2012) 8199-8208.

[22] J. Escobar, Elaboration et caractéristisations de films anodiques composites lubrifiants à base de PTFE sur substrat d'aluminium, Université Toulouse III - Paul Sabatier, 2013.

[23] G.E. Thompson, Porous anodic alumina: fabrication, characterization and applications, Thin Solid Films 297 (1997) 192-201.

[24] C.A. Melendres, S. Van Gils, H. Terryn, Toward a quantitative description of the anodic oxide films on aluminum, Electrochem. Commun. 3 (2001) 737-741.

[25] F. Le Coz, L. Arurault, S. Fontorbes, V. Vilar, L. Datas, P. Winterton, Chemical composition and structural changes of porous templates obtained by anodizing aluminium in phosphoric acid electrolyte, Surf. Interface Anal. 42 (2010) 227-233.

[26] F. Le Coz, L. Arurault, L. Datas, Chemical analysis of a single basic cell of porous anodic aluminium oxide templates, Mater. Charact. 61 (2010) 283-288.

[27] K. Wefers, The mechanism of sealing of anodic oxide coatings on aluminium Part 1 , Aluminium 49 (1973) 553-561.

[28] K. Wefers, The mechanism of sealing of anodic oxide coatings on aluminium Part 2 . Aluminium 49 (1973) 622-624.

[29] G. Patermarakis, N. Papandreadis, Effect of the structure of porous anodic $\mathrm{Al}_{2} \mathrm{O}_{3}$ films on the mechanism of their hydration and pore closure during hydrothermal treatment, Electrochim. Acta 38 (1993) 1413-1420.

[30] L. Domingues, J.C.S. Fernandes, M. Da Cunha Belo, M.G.S. Ferreira, L. Guerra-Rosa, Anodising of Al 2024-T3 in a modified sulphuric acid/boric acid bath for aeronautical applications, Corros. Sci. 45 (2003) 149-160.

[31] G.D. Davis, T.S. Sun, J.S. Ahearn, J.D. Venables, Application of surface behaviour diagrams to the study of hydration of phosphoric acid-anodized aluminium, J. Mater Sci. 17 (1982) 1807-1818.

[32] B.E. Yoldas, Alumina gels that form porous transparent $\mathrm{Al}_{2} \mathrm{O}_{3}$, J. Mater. Sci. 10 (1975) 1856-1860.

[33] P. Alphonse, M. Courty, Structure and thermal behavior of nanocrystalline boehmite Thermochim. Acta 425 (2005) 75-89.

[34] J.W. Diggle, T.C. Downie, C.W. Goulding, Anodic oxide films on aluminum, Chem. Rev. 69 (1969) 365-405.

[35] K. Nagayama, Two-dimensional self-assembly of colloids in thin liquid films, Colloids Surf. Physicochem. Eng. Asp. 109 (1996) 363-374.

[36] P.A. Kralchevsky, K. Nagayama, Capillary interactions between particles bound to interfaces, liquid films and biomembranes, Adv. Colloid Interf. Sci. 85 (2000) 145-192. 
[37] I. Vrublevsky, A. Jagminas, J. Schreckenbach, W.A. Goedel, Electronic properties of electrolyte/anodic alumina junction during porous anodizing, Appl. Surf. Sci. 253 (2007) 4680-4687

[38] L. Arurault, G. Zamora, V. Vilar, P. Winterton, R. Bes, Electrical behaviour, characteristics and properties of anodic aluminium oxide films coloured by nickel electrodeposition, J. Mater. Sci. 45 (2010) 2611-2618.

[39] G. Zamora, L. Arurault, P. Winterton, R. Bes, Impact of the type of anodic film formed and deposition time on the characteristics of porous anodic aluminium oxide films containing Ni metal, Chem. Pap. 65 (2011) 460-468.

[40] T.P. Hoar, G.C. Wood, The sealing of porous anodic oxide films on aluminium, Electrochim. Acta 7 (1962) 333-353.

[41] J. Hitzig, K. Jüttner, W.J. Lorenz, W. Paatsch, AC-impedance measurements on porous aluminium oxide films, Corros. Sci. 24 (1984) 945-952.

[42] J.A. González, V. López, A. Bautista, E. Otero, X.R. Nóvoa, Characterization of porous aluminium oxide films from a.c. impedance measurements, J. Appl. Electrochem. 29 (1999) 229-238.

[43] R. Sprycha, Electrical double layer at alumina/electrolyte interface: I. Surface charge and zeta potential, J. Colloid Interface Sci. 127 (1989) 1-11.

[44] S. Novak, K. König, Fabrication of alumina parts by electrophoretic deposition from ethanol and aqueous suspensions, Ceram. Int. 35 (2009) 2823-2829.
[45] Y. Fukunaka, M. Motoyama, Y. Konishi, R. Ishii, Producing shape-controlled metal nanowires and nanotubes by an electrochemical method, Electrochem. Solid-State Lett. 9 (2006) C62-C64.

[46] A. Ponrouch, M.P. Bichat, S. Garbarino, C. Maunders, G. Botton, P.-L. Taberna, et al. Synthesis and characterization of well aligned Ru nanowires and nanotubes, ECS Trans. 25 (2010) 3-11.

[47] G. Patermarakis, P. Kerassovitou, Study on the mechanism of oxide hydration and oxide pore closure during hydrothermal treatment of porous anodic $\mathrm{Al}_{2} \mathrm{O}_{3}$ films, Electrochim. Acta 37 (1992) 125-131.

[48] Y. Chang, Z. Ling, Y. Li, X. Hu, Hydrothermal synthesis of aluminum oxy-hydroxide nanorod and nanotube arrays, Electrochim. Acta 93 (2013) 241-247.

[49] X. Zhao, Y. Zuo, J. Zhao, J. Xiong, Y. Tang, A study on the self-sealing process of anodic films on aluminum by EIS, Surf. Coat. Technol. 200 (2006) 6846-6853.

[50] H.-J. Oh, K.-W. Jang, C.-S. Chi, Impedance characteristics of oxide layers on aluminium, Bull. Kor. Chem. Soc. 20 (1999) 1340-1344.

[51] F. Mansfeld, C. Chen, C.B. Breslin, D. Dull, Sealing of anodized aluminum alloys with rare earth metal salt solutions, J. Electrochem. Soc. 145 (1998) 2792-2798. 